\title{
La educación superior y los millennials
}

$\mathrm{H}$ oy en día la sociedad ha cambiado su forma tradicional de ver el mundo, originado en gran medida por la evolución de las tecnologías de información y comunicación (TIC), lo que también ha dado un nuevo esquema en la educación superior, pues el grupo de interés que actualmente se encuentra en este nivel de estudios son los jóvenes que nacieron en los últimos tres lustros del siglo pasado y que conocemos como generación millennials. ${ }^{1}$

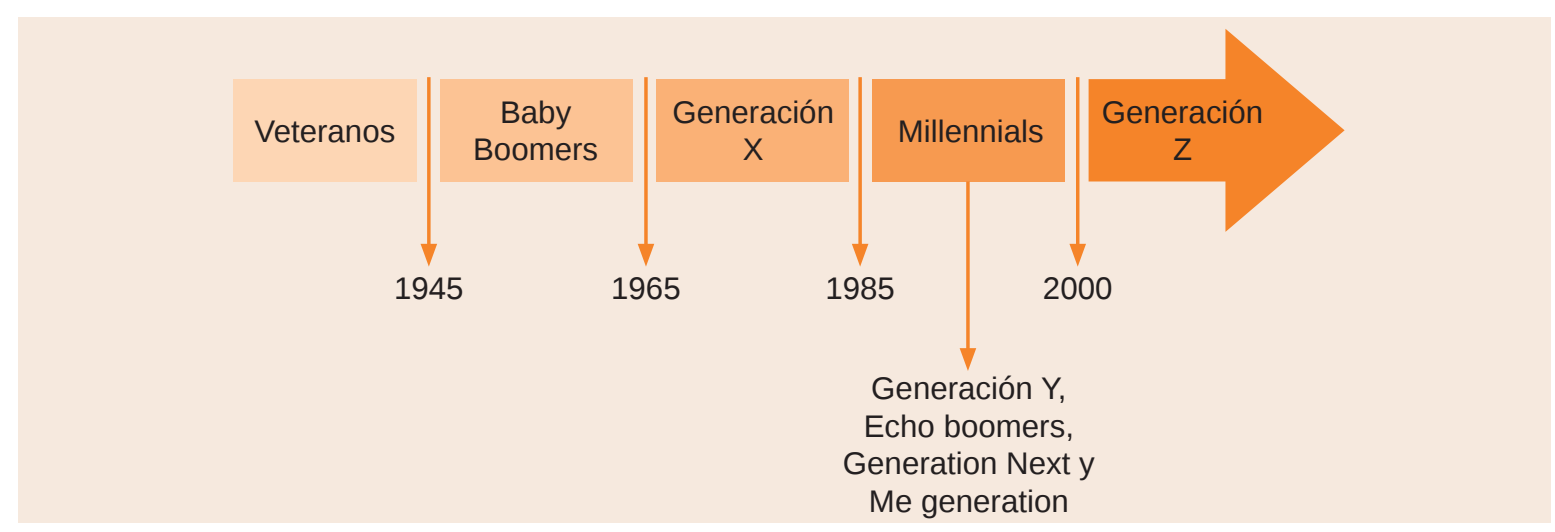

Gráfico 1. Evolución de las generaciones.

Conecta tu marca con los millennials, Carlos Jiménez (2014).

La población de estos jóvenes en Latinoamérica ronda el 30\%, de acuerdo al estudio "Conecta tu marca con los millennials" (Jiménez, 2014) y, según una proyección de la consultora Deloitte (2015), en 2025 repre-

\section{《a nueva educación debe hacer uso de una amplia gama de canales y dispositivos para mantener una comunicación y experiencia con los estudiantes. \)} sentarán $75 \%$ de la fuerza laboral del mundo.

En México, esta cifra está cercana a los 46 millones (Miller, 2015). Es por ello que las estrategias de educación deben estar enfocadas en las nuevas necesidades y demandas de este grupo de interés, quienes entre sus características tienen un fuerte dominio de la tecnología y la ven como si fuera una extensión común de su vida. Casi todas sus relaciones cotidianas son por medio de una pantalla, es decir, son nativos digitales.

1 Los millenials -también llamados "Generación Y"- son un grupo de jóvenes que nacieron a principios de los años ochenta hasta los primeros años del 2000. (Millennials Rising: The Next Great Generation de W. Strauss). 
Distribución de la población en Latinoamérica

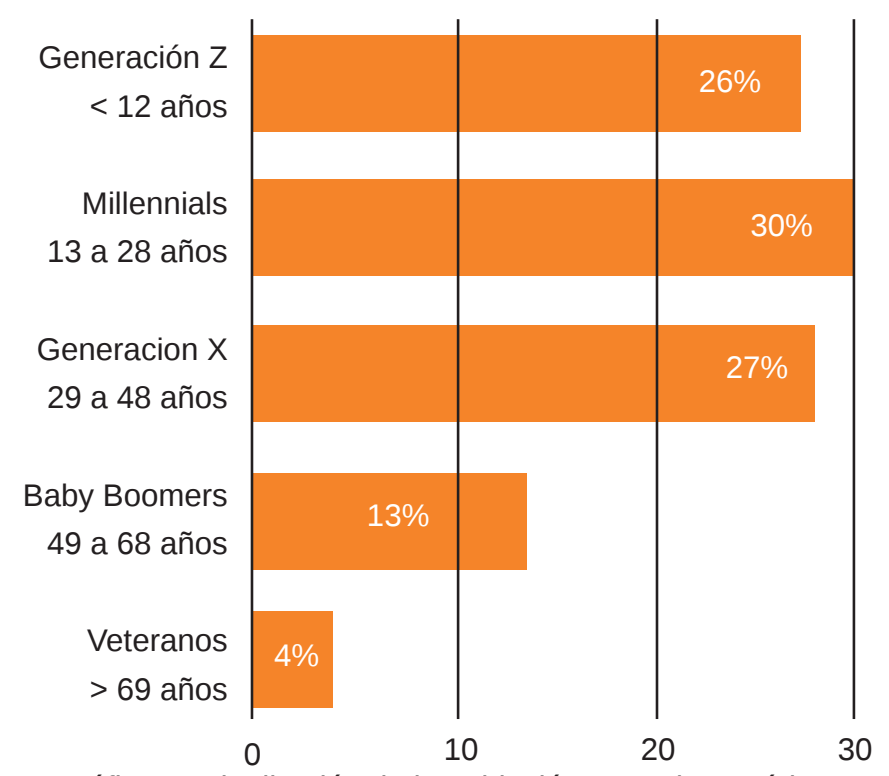

Gráfico 2. Distribución de la población en Latinoamérica.

Conecta tu marca con los millennials, Carlos Jiménez (2014).

Por otro lado, los millennials son multitareas o multitask, esto es, tienen la capacidad o necesidad de realizar varias acciones al mismo tiempo; por ello, la nueva educación debe hacer uso de una amplia gama de canales y dispositivos para mantener una comunicación y experiencia con los estudiantes que favorezca el cumplimiento de los objetivos de aprendizaje. Tomando en cuenta lo anterior, se considera que los nuevos procesos de enseñanza y aprendizaje con la generación millennials se denominan omnicanalidad, por ello las estrategias pedagógicas deben ser integradas de manera on y offline; así mismo, la concepción multiplataforma y la narrativa transmedia se impondrán en la comunicación con los alumnos y en la forma de transmitir conocimientos.

La acción y reacción se presenta de manera móvil y su pantalla principal de entrada de información es la de un dispositivo móvil. En México, 78\% de los millennials posee un smartphone (Telefónica Global Millennial Survey, 2014), se podría decir que esta generación se considera nomofóbica. ${ }^{2}$

Otro aspecto fundamental en la cultura y la demanda de los millennials, es el impulso extraordinario en el crecimiento de las aplicaciones

2 El término nomofobia es la abreviatura de la expresión inglesa "no mobile phone phobia", esto es, el miedo a estar sin teléfono móvil.

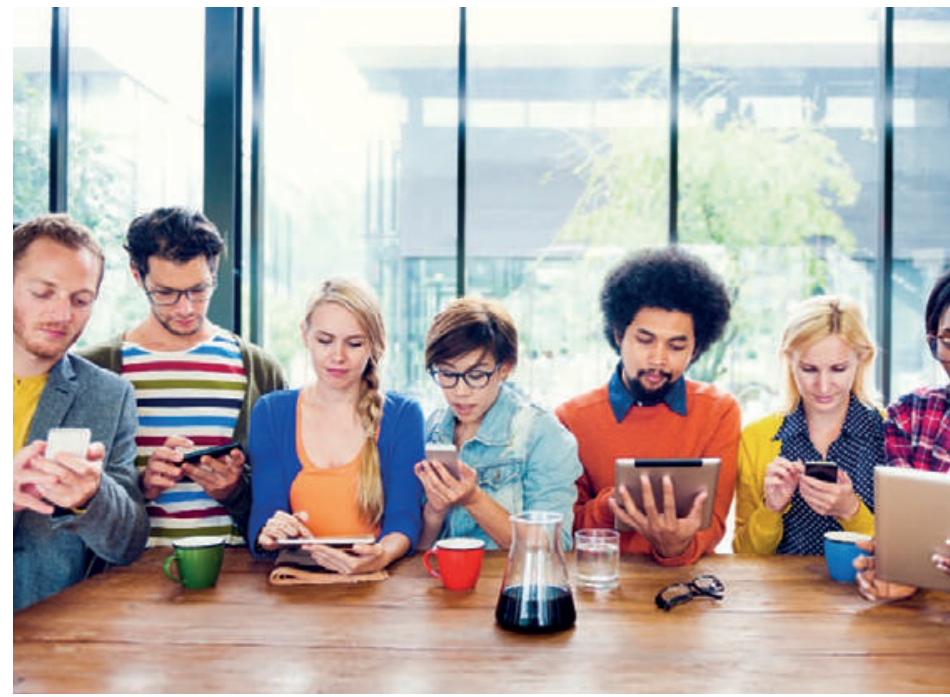

Imagen 1. El contexto de los millennials. Creative Commons.

móviles, por lo que se pueden considerar appdictos. Ante esta situación, los modelos de aprendizaje y estudio dentro y fuera de las aulas se deben construir y mejorar aprovechando la funcionalidad de las aplicaciones móviles, ya que se han convertido en una potente herramienta de comunicación y transferencia de información que permiten mejorar la experiencia de aprendizaje de los estudiantes. 
Otro aspecto que caracteriza a los jóvenes millennials es su fuerte participación en las redes sociales, además de ser más críticos y exigentes en estos medios, demandan personalización y nuevos valores provenientes de diversas fuentes, tales como instituciones de gobierno, universidades, empresas $\mathrm{y}$ de la sociedad en general. Hay que considerar que tan sólo en Latinoamérica, $88 \%$ de los millennials cuenta con un perfil en redes sociales, por lo que consultan, comparten y comentan a través de diversos medios; los más utilizados hoy en día son los llamados smartphones o teléfonos inteligentes, así como otros dispositivos móviles como las tablets, lo anterior ha elevado el nivel de comunicación horizontal y su experiencia digital.

Todo lo anterior determina la forma de actuar y pensar dentro y fuera

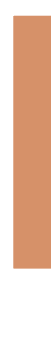
del aula, es momento de que los modelos de aprendizaje cambien radicalmente para alcanzar el éxito en la enseñanza. Los estudiantes millennials están fuertemente influenciados por una gran cantidad de insights ${ }^{3}$ provenientes de Internet y éstos son la clave que les permite encontrar la solución a un problema, un camino, un dato que les sugiere cómo resolver cualquier ecuación, por compleja que sea. Pero ojo, porque el insight no es la solución, es simplemente el punto que los lleva al camino de esa solución.

En el ámbito laboral, según datos de Deloite en su Encuesta Millennials 2016, más de 60\% de los millennials expresan su sentimiento de querer dejar su organización para el 2020, es por ello que los negocios tienen que construir estrategias para generar lealtad con este grupo de colaboradores o arriesgarse a perder un gran porcentaje de su fuerza de trabajo e incluso a los mejores talentos.

Page Personnel (2014), firma consultora de reclutamiento especializado, señala que se ha encontrado que a los millennials les gusta ser incluidos en la toma de decisiones importantes, así como sa-

3 Un insight es un término inglés que significa "mirar hacia adentro", se entiende como un fenómeno cognitivo en el que se llega a la solución o comprensión de un conflicto en asociación con una vivencia afectiva de sorpresa y certeza ante el descubrimiento. ber que están aportando un valor agregado a la empresa, buscan que los líderes de las organizaciones los formen como personas y sean sus guías durante su carrera profesional, en este sentido, la universidad debe virar su rumbo en el tipo y forma de llevar el servicio social y prácticas profesionales.

Actualmente, un universitario millennial valora la participación y la colaboración, prefiere compartir a poseer y exige nuevos valores como la transparencia, la sostenibilidad y el compromiso social. Aquellas organizaciones que sepan implicar a este grupo de jóvenes, permitiéndoles aportar sus ideas en la creación y el desarrollo y sentirse parte de un proceso o actividad, conquistarán el corazón de los millennials.

La contratación de este talento tiene claros beneficios, pues su adaptación a la cultura corporativa es mucho más rápida, tienen hambre de aprender y combinan el desarrollo de procesos antiguos con innovaciones que generan oportunidades de crecimiento para las organizaciones y que se coloque en posiciones estratégicas, todo esta nueva cultura será un reto a consolidar por parte de las universidades del país.

Considerando lo anterior, el Modelo Educativo Institucional de la UAA (2007: 6) "plantea como finalidad última de su quehacer educativo la formación de sus estudiantes, ya que, son ellos la razón de ser de la institución", y por ello "busca facilitar a los estudiantes de los distintos programas educativos que ofrece la institución, una formación humanista que comprenda el desarrollo equilibrado e integral de las dimensiones de su persona". En este sentido, la UAA ha desdoblado una gran cantidad de recursos para implementar acciones pedagógicas acorde con este nuevo enfoque de aprendizaje y en el cual los jóvenes millenniales se desenvuelvan de manera cotidiana. Prueba de ello es la implementación del recurso de "Ámbito Académico", donde los profesores y estudiantes pueden interactuar a través del espacio "Aula Virtual" por medio de chats, foros, wikis, entre otra serie de herramientas de gran apoyo y valía del proceso de enseñanza-aprendizaje. 
Fuentes de consulta

Deloitte. (2015). Brechas importantes. Encuesta Deloitte 2015. Generación del Milenio. México: DTTL Global Brand \& Communications. Deloitte. (2016). Los millennials y los empleadores: ¿Podrá salvarse esta relación? Encuesta Deloitte 2016. Generación del Milenio. México: Galaz, Yamazaki, Ruiz Urquiza, s. c.

Jiménez, C. (2014). Conecta tu marca con los millennials. México: Tendencias Digitales.

Miller, D. (2015). Paradojas de los millennials a la mexicana. Tribuna Milenio. Recuperado el 27 julio 2016, en: http://bit.ly/1hitKVa.
Page Personnel. (2014). Reclutar millennials: el gran reto de las compañías mexicanas. Agosto 2016, de Page Personnel Group, en: http://bit.ly/2fZWCpg.

Telefónica Global Millennial Survey. (2014). Telefónica Global Millennial Survey Global. Recuperado el 28 de julio 2016, en: http:// static.pulso.cl/20141015/2019231.pdf.

Universidad Autónoma de Aguascalientes. (2007). Modelo Educativo Institucional, en Correo Universitario, sexta época, No. 16, publicado el 15 de marzo de 2007. México: UAA.

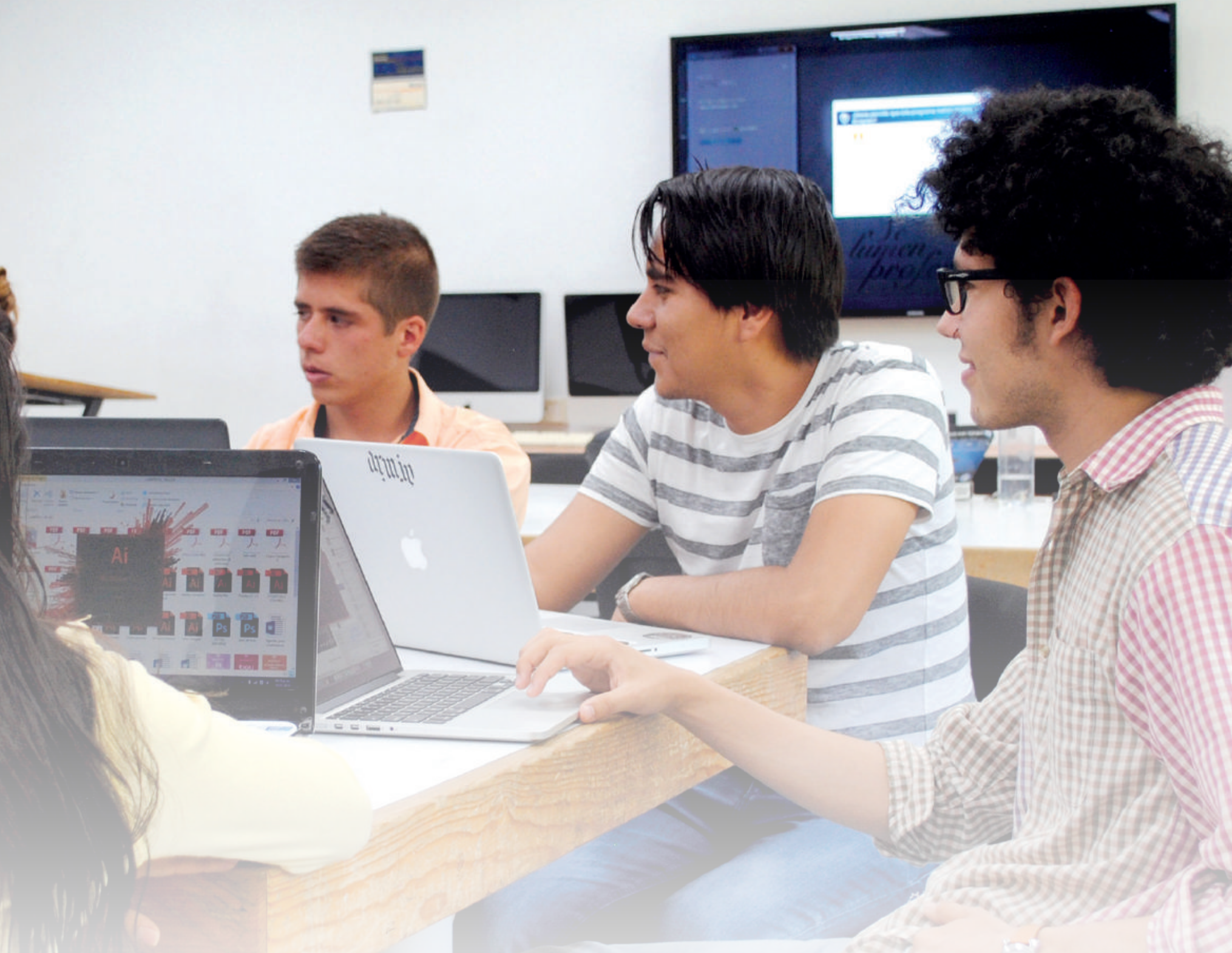

